\title{
Differences in clinical features between laparoscopy and open resection for primary tumor in patients with stage IV colorectal cancer
}

This article was published in the following Dove Press journal:

OncoTargets and Therapy

19 November 2015

Number of times this article has been viewed

\author{
Ik Yong Kim ${ }^{1, *}$ \\ Bo $\mathrm{Ra} \mathrm{Kim}{ }^{2, *}$ \\ Hyun Soo Kim² \\ Young Wan Kim' \\ 'Department of Surgery, Division \\ of Colorectal Surgery, ${ }^{2}$ Department \\ of Internal Medicine, Division of \\ Gastroenterology, Yonsei University \\ Wonju College of Medicine, Wonju, \\ Gangwon-do, Korea \\ *These authors contributed equally \\ to this work
}

Purpose: To identify differences in clinical features between laparoscopy and open resection for primary tumor in patients with stage IV colorectal cancer. We also evaluated short-term and oncologic outcomes after laparoscopy and open surgery.

Methods: A total of 100 consecutive stage IV patients undergoing open $(n=61)$ or laparoscopic $(n=39)$ major resection were analyzed. There were four cases $(10 \%)$ of conversion to laparotomy in the laparoscopy group.

Results: Pathological T4 tumors ( $56 \%$ vs $26 \%$ ), primary colon cancers ( $74 \%$ vs $51 \%$ ), and larger tumor diameter ( $6 \mathrm{vs} 5 \mathrm{~cm}$ ) were more commonly managed with open surgery. Right colectomy was more common in the open surgery group (39\%) and low anterior resection was more common in the laparoscopy group $(39 \%, P=0.002)$. Hepatic metastases in segments II, III, IVb, V, and VI were more frequently resected with laparoscopy (100\%) than with open surgery $(56 \%)$, although the difference was not statistically significant. In colon and rectal cancers, mean operative time and 30-day complication rates of laparoscopy and open surgery did not differ. In both cancers, mean time to soft diet and length of hospital stay were shorter in the laparoscopy group. Mean time from surgery to chemotherapy commencement was significantly shorter with laparoscopy than with open surgery. In colon and rectal cancers, 2-year cancer-specific and progression-free survival rates were similar between the laparoscopy and open surgery groups.

Conclusion: Based on our findings, laparoscopy can be selected as an initial approach in patients with a primary tumor without adjacent organ invasion and patients without primary tumor-related symptoms. In selected stage IV patients, tumor factors such as primary rectal tumor, peritoneal carcinomatosis, or liver metastasis may not be absolute contraindications for a laparoscopic approach.

Keywords: colorectal neoplasms, laparoscopy, neoplasm metastasis

\section{Introduction}

Laparoscopy for colorectal cancer has numerous short-term benefits such as less postoperative pain, shorter hospital stay, and an earlier return to work. ${ }^{1-3}$ In addition, laparoscopy is as effective as open surgery in terms of oncologic outcomes. ${ }^{4,5}$ However, information regarding optimal indications for laparoscopy is not readily available in patients with stage IV colorectal cancer, because a metastatic disease is frequently excluded from clinical trials.

Approximately $20 \%-25 \%$ of patients have synchronous metastasis at the initial diagnosis of colorectal cancer., ${ }^{6,7}$ There are various clinical scenarios regarding optimal first-line treatment in patients with stage IV disease. ${ }^{8,9}$ Removal of the primary tumor only, synchronous resection of metastatic tumor, or first-line chemotherapy
Correspondence: Young Wan Kim Department of Surgery, Division of Colorectal Surgery, Yonsei University Wonju College of Medicine, 20 Ilsan-ro, Wonju, Gangwon-do, 220-70I, Korea $\mathrm{Tel}+82337410573$

Fax +82 337410574

Email youngwkim@yonsei.ac.kr 
can be considered. The primary tumor should be resected in symptomatic patients, but this method is still controversial in patients without primary tumor-related symptoms. ${ }^{10}$ Surgeons should determine which is the most appropriate treatment strategy. If a first-line surgery is chosen for primary tumor resection, either laparoscopy or open surgery must be selected.

Several studies have compared outcomes between laparoscopy and open surgery in patients with stage IV disease, and all reported favorable short-term ${ }^{11-18}$ and comparable oncologic outcomes ${ }^{11-16,18}$ between the two approaches. However, the clinical features associated with selecting surgical approaches such as laparoscopy or open resection for stage IV disease have not been investigated extensively. We postulated that certain patient or tumor factors are related to selecting surgical approaches and that identifying these factors could offer surgeons objective evidence and allow more patients with stage IV disease to be managed with a laparoscopic approach. This study aimed to identify differences in clinical features between laparoscopy and open resection for primary tumor in patients with stage IV colorectal cancer. We also evaluated short-term and oncologic outcomes after laparoscopy and open surgery.

\section{Methods}

\section{Patients}

This is a retrospective clinical study at a single tertiary center. The STrengthening the Reporting of OBservational studies in Epidemiology guidelines were used to report this observational study. ${ }^{19}$ This study was approved by the Institutional Review Board of Wonju Severance Christian Hospital (YWMR-14-5-080). Between March 1, 2007 and December 31, 2012, 100 consecutive patients undergoing primary tumor resection for stage IV colorectal cancer were enrolled. Eligibility criteria included patients with histologically confirmed colorectal cancer who underwent major colorectal resection with or without liver resection. Patients undergoing extra-abdominal organ surgery (eg, pneumonectomy), nonresectional procedures for colorectal cancer, emergent operation, or bypass procedures for colorectal cancer were excluded from this study population.

\section{Study purposes}

The primary purpose was to identify differences in clinical features between laparoscopy and open surgery for primary tumor resection in patients with stage IV colorectal cancer. The secondary purpose was to evaluate short-term and oncologic outcomes after laparoscopy and open surgery.

\section{Surgery, chemotherapy, and follow-up}

All surgeries were performed by two colorectal surgeons. Type of surgical procedure, either laparoscopic or open, was decided at the surgeon's discretion. Laparoscopic and open procedures were explained to patients and their families before surgery, and informed consent was obtained from all patients. After standardized preoperative preparation, affected colon and rectal segments were removed based on standard surgical procedures. ${ }^{20,21}$ Detailed operative procedures are described elsewhere. ${ }^{22}$ All patients were registered in a prospectively maintained colorectal database after surgery and followed at 3- or 6-month intervals for 5 years and then yearly thereafter.

After recovery from surgery, all stage IV patients were recommended to receive chemotherapy according to the National Comprehensive Cancer Network guidelines. ${ }^{8,9}$ Chemotherapy regimens included 5-fluorouracil with leucovorin, capecitabine, or oxaliplatin/irrinotecan, or in combination with targeted agents.

\section{Outcome measures}

All laparoscopic data were analyzed according to the intentionto-treat principle. Postoperative complications were defined as events that required additional treatment within 30 days of surgery, based on the Clavien-Dindo classification. ${ }^{23}$ Conversion to open surgery was defined as stopping the laparoscopic approach and using a conventional laparotomy incision to complete the surgical procedure. Treatments requiring admission to an intensive care unit (ICU) or blood transfusions were included when patients needed these interventions within 48 hours after primary surgery. ICU admissions and transfusions due to postoperative complications were not considered.

\section{Statistical analysis}

All statistical analyses were performed using IBM SPSS Statistics for Windows, Version 21.0 (IBM, Armonk, NY, USA) and MedCalc Statistical Software, Version 15.2.2 (MedCalc Software bvba, Ostend, Belgium). Categorical variables were described by frequencies and percentages, and were compared by chi-square test or Fisher's exact tests when appropriate. Continuous variables were described as mean and standard deviation, and were analyzed by Student's $t$-test. Survival analysis was performed by the Kaplan-Meier method with log rank tests. $P<0.05$ was considered statistically significant.

\section{Results}

\section{Patient characteristics}

A total of 100 consecutive stage IV patients were analyzed based on primary surgical approach of open $(n=61)$ or 
laparoscopic procedures $(\mathrm{n}=39)$. Pathological T4 tumors ( $56 \%$ vs $26 \%$ ), primary colon cancers ( $74 \%$ vs $51 \%$ ), and larger tumor diameter ( 6 vs $5 \mathrm{~cm}$ ) were more commonly observed in the open surgery group than the laparoscopy group. There were no significant differences in age, sex, American Society of Anesthesiologists (ASA) score, body mass index, and history of previous abdominal surgery between the open and laparoscopy groups.

In terms of operation types, right colectomy was more common in the open surgery group (39\%) and low anterior resection was more common in the laparoscopy group $(39 \%, P=0.002)$. Proportions with liver resection did not differ between the two groups. Although the difference was not statistically significant, hepatic metastases in segments II, III, IVb, V, and VI were more frequently managed with laparoscopy $(100 \%)$ than with open surgery $(56 \%)$. There were four cases $(10 \%)$ of conversion to laparotomy in the laparoscopy group, and all were colon cancer cases. Tumor fixation to adjacent organs $(n=3)$ and thorough irrigation of the abdominal cavity due to a perforated tumor $(n=1)$ were reasons for open conversion. The $\mathrm{R} 0$ resection rate was $41 \%$ in the laparoscopy group and $26 \%$ in the open surgery group $(P=0.132)$. Detailed patient characteristics are presented in Table 1.

\section{Primary tumor-related symptoms}

Asymptomatic patients with colon cancer were more frequently managed with laparoscopy ( $35 \%$ vs $13 \%, P=0.044)$. Similarly, asymptomatic patients with rectal cancer were more commonly treated with laparoscopy (37\% vs $6 \%$, $P=0.032$ ). Obstruction was the most common symptom in both colon and rectal cancer groups (Table 2).

\section{Short-term outcomes}

In patients with colon cancer, mean operative time (175 vs 174 minutes) and blood loss did not differ between the two groups. There were no differences in 30-day complication rates between laparoscopy (25\%) and open surgery (44\%) $(P=0.779)$. There was one death from pneumonia in a patient with underlying chronic obstructive pulmonary disease in the open surgery group. ICU admissions $(P=0.010)$ and blood transfusions $(P=0.019)$ were more common in the open

Table I Patient characteristics

\begin{tabular}{|c|c|c|c|c|}
\hline \multirow[t]{2}{*}{ Variables } & \multirow[t]{2}{*}{ Values } & \multirow{2}{*}{$\frac{\text { Laparoscopy }(n=39)}{\mathbf{N}(\%)}$} & \multirow{2}{*}{$\frac{\text { Open }(n=6 I)}{N(\%)}$} & \multirow[t]{2}{*}{$P$-value } \\
\hline & & & & \\
\hline Age (years) & Mean (SD) & $69(12)$ & $69(\mathrm{II})$ & 0.997 \\
\hline Sex & Male & $22(56)$ & $38(62)$ & 0.558 \\
\hline ASA score & $\geq 3$ & $7(18)$ & $15(25)$ & 0.434 \\
\hline Body mass index $\left(\mathrm{kg} / \mathrm{m}^{2}\right)$ & Mean (SD) & $23(4)$ & $22(4)$ & 0.756 \\
\hline T4 tumor & + & $10(26)$ & $34(56)$ & 0.003 \\
\hline Previous laparotomy & + & $2(5)$ & $7(I I)$ & 0.279 \\
\hline \multirow[t]{2}{*}{ Primary tumor } & Colon & $20(5 \mathrm{I})$ & $45(74)$ & 0.021 \\
\hline & Rectum & $19(49)$ & $16(26)$ & \\
\hline \multirow[t]{6}{*}{ Site of metastasis } & Liver & $21(54)$ & $33(54)$ & 0.390 \\
\hline & Lung & $6(15)$ & $5(8)$ & \\
\hline & Peritoneum & $5(13)$ & $9(15)$ & \\
\hline & Lymph node & $3(8)$ & I (2) & \\
\hline & Bone & I (3) & $2(3)$ & \\
\hline & Multiorgan & $3(8)$ & II (I8) & \\
\hline \multirow[t]{6}{*}{ Primary tumor resection } & Abdominoperineal resection & $6(15)$ & $14(23)$ & 0.002 \\
\hline & Hartmann's procedure & & & \\
\hline & Low anterior resection & $15(39)$ & $8(13)$ & \\
\hline & Left colectomy & II (28) & $9(15)$ & \\
\hline & Subtotal colectomy & $0(0)$ & $6(10)$ & \\
\hline & Right colectomy & 7 (18) & $24(39)$ & \\
\hline Conversion to open surgery & + & $4(10)$ & - & - \\
\hline Liver resection & + & $5(13)$ & $16(26)$ & 0.108 \\
\hline \multirow[t]{2}{*}{ Resected liver segments } & II, III, IVb, V, VI & $9(56)$ & $5(100)$ & 0.070 \\
\hline & IVa, VII, VIII & 7 (44) & $0(0)$ & \\
\hline CEA (ng/mL) & Median (interquartile range) & $6(3-27)$ & $9(3-59)$ & 0.349 \\
\hline Tumor diameter $(\mathrm{cm})$ & Mean (SD) & $4.9(2)$ & $6.2(2)$ & 0.006 \\
\hline $\mathrm{R} 0$ resection & + & $16(4 \mid)$ & $16(26)$ & 0.132 \\
\hline
\end{tabular}

Abbreviations: SD, standard deviation; ASA, American Society of Anesthesiologists; CEA, carcinoembryonic antigen. 
Table 2 Primary tumor-related symptoms

\begin{tabular}{|c|c|c|c|c|c|c|}
\hline \multirow[t]{3}{*}{ Variables } & \multicolumn{3}{|l|}{ Colon } & \multicolumn{3}{|l|}{ Rectum } \\
\hline & Laparoscopy & Open & $P$-value & Laparoscopy & Open & $P$-value \\
\hline & $\mathbf{N}(\%)$ & $\mathbf{N}(\%)$ & & $\mathbf{N}(\%)$ & N (\%) & \\
\hline Asymptomatic & $7(35)$ & $6(13)$ & 0.044 & $7(37)$ & I (6) & 0.032 \\
\hline Symptomatic & $13(65)$ & $39(87)$ & & $12(63)$ & $15(94)$ & \\
\hline Obstruction & $8(40)$ & $19(42)$ & 0.320 & $6(32)$ & $5(3 I)$ & 0.078 \\
\hline Perforation & I (5) & $3(7)$ & & $2(I I)$ & $2(13)$ & \\
\hline Bleeding, anemia & $2(10)$ & $9(20)$ & & $4(2 I)$ & $4(25)$ & \\
\hline Pain & $2(10)$ & $8(18)$ & & $0(0)$ & $4(25)$ & \\
\hline
\end{tabular}

surgery group. Time to soft diet ( 4 vs 6 days, $P=0.019$ ) and length of hospital stay ( 11 vs 17 days, $P=0.001$ ) were shorter in the laparoscopy group. The percentages of patients who received chemotherapy were $65 \%$ in the laparoscopy group and $64 \%$ in the open surgery group $(P=0.966)$. Mean time from surgery to chemotherapy commencement was significantly shorter with laparoscopy (32 days) than with open surgery (40 days, $P=0.020$ ).

In patients with rectal cancer, mean operative time (212 vs 225 minutes, $P=0.687$ ) and blood loss did not differ between the two groups. There were no differences in 30-day complication rates between laparoscopy (26\%) and open surgery $(19 \%)(P=0.595)$. ICU admission $(P=0.013)$ was more common in the open surgery group. Time to soft diet ( 4 vs 6 days, $P=0.044$ ) and length of hospital stay (10 vs 18 days, $P=0.037$ ) were shorter in the laparoscopy group. The percentages of patients who received chemotherapy was $74 \%$ in the laparoscopy group and $69 \%$ in the open surgery group $(P=0.748)$. Mean time from surgery to chemotherapy commencement was significantly shorter with laparoscopy (29 days) than with open surgery (38 days, $P=0.032$ ) (Table 3).

Table 3 Short-term outcomes

\begin{tabular}{|c|c|c|c|c|c|c|c|}
\hline \multirow[t]{3}{*}{ Variables } & \multirow[t]{3}{*}{ Values } & \multicolumn{3}{|l|}{ Colon } & \multicolumn{3}{|l|}{ Rectum } \\
\hline & & \multirow{2}{*}{$\begin{array}{l}\text { Laparoscopy } \\
\mathbf{N}(\%)\end{array}$} & \multirow{2}{*}{$\begin{array}{l}\text { Open } \\
\mathbf{N}(\%)\end{array}$} & \multirow[t]{2}{*}{$P$-value } & \multirow{2}{*}{$\begin{array}{l}\text { Laparoscopy } \\
\mathbf{N}(\%)\end{array}$} & \multirow{2}{*}{$\begin{array}{l}\text { Open } \\
\mathbf{N}(\%)\end{array}$} & \multirow[t]{2}{*}{$P$-value } \\
\hline & & & & & & & \\
\hline Operative time (min) & Mean (SD) & $175(59)$ & $174(74)$ & 0.955 & $212(9 \mid)$ & $225(95)$ & 0.687 \\
\hline Estimated blood loss (mL) & Mean (SD) & $100(14 I)$ & II 8 (274) & 0.779 & $125(172)$ & $333(530)$ & 0.151 \\
\hline 30-day complication & + & $5(25)$ & $20(44)$ & 0.137 & $5(26)$ & $3(19)$ & 0.595 \\
\hline 30-day mortality & + & $0(0)$ & I (2) & 0.502 & $0(0)$ & $0(0)$ & - \\
\hline Clavien-Dindo score & $\geq 3$ & $2(10)$ & $9(20)$ & 0.321 & $5(26)$ & $2(13)$ & 0.309 \\
\hline \multirow[t]{8}{*}{ Type of complication* } & Pulmonary & 0 & 4 & & 1 & 1 & \\
\hline & Wound & 3 & 9 & & 2 & 2 & \\
\hline & Leakage & 0 & 1 & & 1 & 1 & \\
\hline & Bleeding & 0 & 0 & & 0 & 0 & \\
\hline & Abscess & 0 & 1 & & 1 & 0 & \\
\hline & lleus & 1 & 4 & & 0 & 1 & \\
\hline & Urinary & 0 & 2 & & 0 & 0 & \\
\hline & Other & 1 & 3 & & 1 & 0 & \\
\hline Intensive care unit admission & + & $2(10)$ & $19(42)$ & 0.010 & $4(2 I)$ & $10(63)$ & 0.013 \\
\hline Blood transfusion & + & $4(20)$ & $23(5 \mathrm{I})$ & 0.019 & $9(47)$ & $10(63)$ & 0.371 \\
\hline Time to soft diet (day) & Mean (SD) & $4(2)$ & $6(3)$ & 0.037 & $4(1)$ & $6(5)$ & 0.044 \\
\hline Hospital stay (day) & Mean (SD) & II (3) & $17(11)$ & 0.001 & $10(4)$ & $18(12)$ & 0.037 \\
\hline Postoperative chemotherapy & + & $13(65)$ & $29(64)$ & 0.966 & $14(74)$ & II (69) & 0.748 \\
\hline \multirow[t]{4}{*}{ Chemotherapy regimen } & Fluoropyrimidine & $3(15)$ & $7(16)$ & 0.629 & $3(16)$ & $3(19)$ & 0.912 \\
\hline & FOLFOX & $5(25)$ & $9(20)$ & & $6(32)$ & $5(3 I)$ & \\
\hline & FOLFIRI & I (5) & $8(18)$ & & $4(21)$ & $3(19)$ & \\
\hline & Targeted agents & $4(20)$ & $5(I I)$ & & I (5) & $0(0)$ & \\
\hline Time to chemotherapy initiation (days) & Mean (SD) & $32(6)$ & $40(16)$ & 0.020 & $29(6)$ & $38(\mathrm{II})$ & 0.032 \\
\hline
\end{tabular}

Note: *Eight of 33 patients (24\%) had more than one type of complication.

Abbreviations: SD, standard deviation; FOLFOX, folinic acid, fluorouracil, oxaliplatin; FOLFIRI, irinotecan with fluorouracil and folinic acid; min, minutes. 


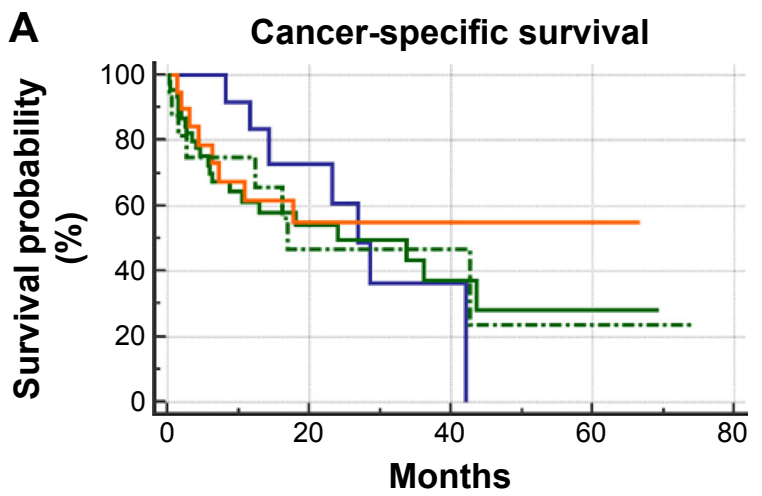

Number at risk

Group: lap, colon

$\begin{array}{ccccc}20 & 6 & 1 & 0 & 0 \\ \begin{array}{cccc}\text { Group: open, colon } \\ 45\end{array} & 14 & 4 & 3 & 0 \\ \begin{array}{c}\text { Group: lap, rectum } \\ 19\end{array} & 7 & 2 & 1 & 0 \\ \text { Group: open, rectum } & & & & \end{array}$

16

3

\begin{abstract}
2
\end{abstract}
1

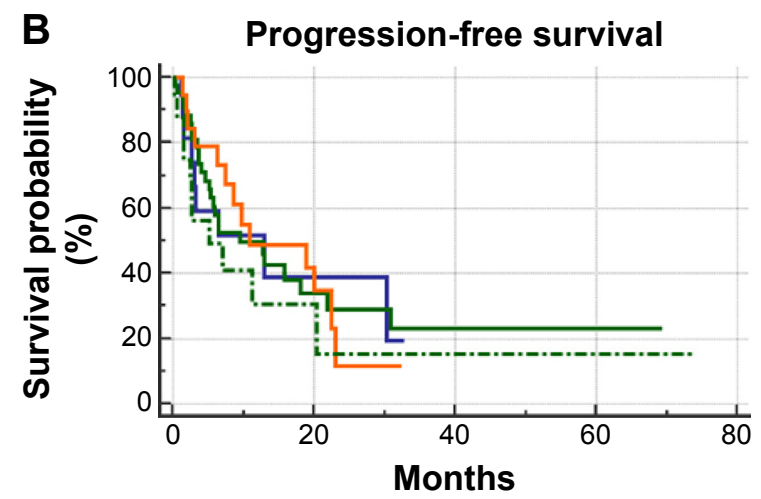

Number at risk

Group: lap, colon

19
Group: open, colon
45
Group: lap, rectum
19

Group: open, rectum

16

2

0

2

0

1

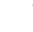

(1)

\author{
0 \\ 0 \\ 0 \\ 0
}

Figure I Kaplan-Meier survival analysis.

Notes: (A) In colon cancer, 2-year cancer-specific survival rates were $60.8 \%$ and $49.8 \%$ for the laparoscopy and open surgery groups, respectively ( $P=0.590)$. In rectal cancer, 2 -year cancer-specific survival rates were $54.9 \%$ and $46.9 \%$ for the laparoscopy and open surgery groups, respectively $(P=0.598)$. (B) In colon cancer, 2 -year progression-free survival rates were $38.8 \%$ and $29.1 \%$ for the laparoscopy and open surgery groups, respectively $(P=0.8 \mid 5)$. In rectal cancer, 2 -year progression-free survival rates were II.6\% and $15.4 \%$ for the laparoscopy and open surgery groups, respectively $(P=0.284)$.

Abbreviation: Lap, laparoscopy.

\section{Oncologic outcomes}

Kaplan-Meier survival analysis showed that in patients with colon cancer, 2-year cancer-specific survival rates were $60.8 \%$ and $49.8 \%$ for the laparoscopy and open surgery groups, respectively $(P=0.590)$. In patients with rectal cancer, 2-year cancer-specific survival rates were $54.9 \%$ and $46.9 \%$ for the laparoscopy and open surgery groups, respectively $(P=0.598)$ (Figure 1A).

In colon cancer, 2-year progression-free survival rates were $38.8 \%$ and $29.1 \%$ for the laparoscopy and open surgery groups, respectively $(P=0.815)$. In rectal cancer, 2-year progression-free survival rates were $11.6 \%$ and $15.4 \%$ for the laparoscopy and open surgery groups, respectively $(P=0.284)$ (Figure 1B).

\section{Discussion}

The major finding of this study is that tumor factors such as pathological T4 tumors ( $56 \%$ vs $26 \%$ ), primary colon cancers ( $74 \%$ vs $51 \%$ ), and larger tumor diameter (6 vs $5 \mathrm{~cm}$ ) were related to selecting a surgical approach (open resection) for primary tumor resection. Patients with asymptomatic primary tumor were more frequently managed by laparoscopy (colon cancer: $35 \%$ vs $13 \%, P=0.044$ and rectal cancer: $37 \%$ vs $6 \%, P=0.032$ ). Laparoscopy for primary tumor resection was associated with short-term advantages such as less ICU admission, shorter time to soft diet, reduced length of hospital stay, and shorter time from surgery to chemotherapy commencement in patients with both colon and rectal cancers. Cancer-specific and progression-free survival rates were also similar between the laparoscopy and open surgery groups in patients with colon and rectal cancers.

\section{Clinical features}

Success of laparoscopy is affected by patient, tumor, and surgeon factors. ${ }^{24}$ Patient or tumor factors include primary tumor-related symptoms, intra-abdominal adhesion, visceral obesity, comorbidities, and locally advanced tumor. If surgical difficulties are anticipated, surgeons tend to abandon a laparoscopic approach. ${ }^{25}$ When considering laparoscopic resection for primary tumors in patients with stage IV disease, the choice of laparoscopy or open surgery is largely dependent on the surgeon, ${ }^{11,12,16,18}$ patient, ${ }^{15}$ or both. ${ }^{13,14}$ Objective data regarding laparoscopic indications are lacking. Only one study has described the exclusion of patients with adjacent organ invasion ${ }^{17}$ (Table 4). 


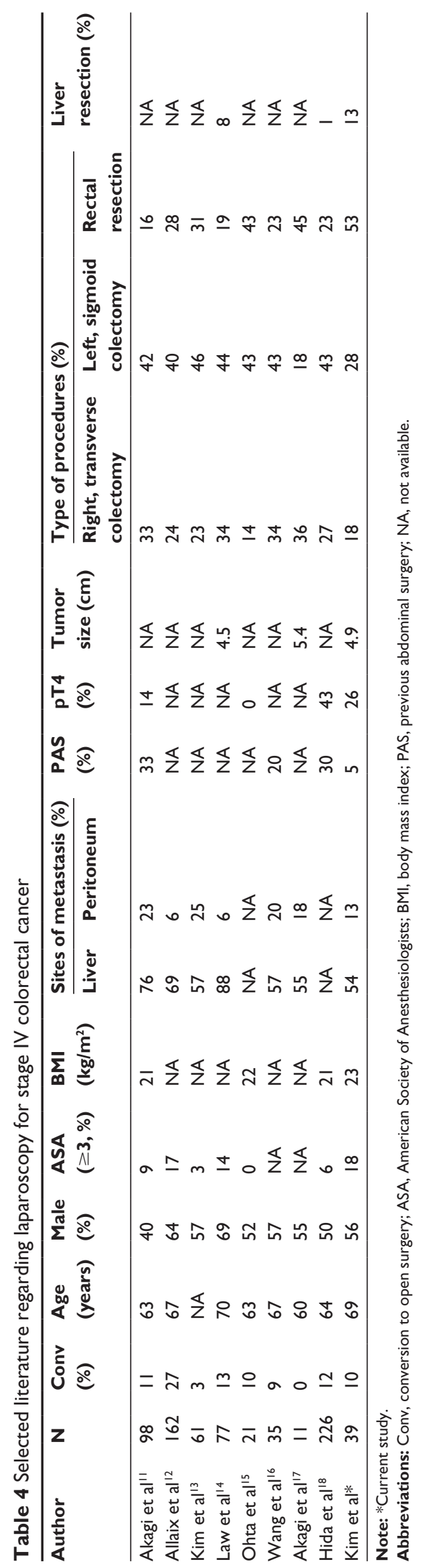

In our study, difficult surgical situations such as pT4 tumors and larger tumors were more frequently managed with an open surgical approach. The proportion of T4 tumors was $14 \%{ }^{11}$ and $43 \%{ }^{18}$ in previous studies and $26 \%$ in our study. Mean tumor size was $4.5^{14}$ and $5.4 \mathrm{~cm}^{17}$ in earlier studies and $4.9 \mathrm{~cm}$ in this study. Rectal resection varied from $16 \%$ to $45 \%{ }^{11-18}$ and was $53 \%$ in this study. Allaix et al ${ }^{12}$ reported that primary rectal cancer as well as a bulky tumor increased conversion to laparotomy. In this study, colon cancer (specifically right hemicolectomy) was more commonly managed with an open surgical approach, partly due to difficulties in stenting for proximal colon obstruction. Obstruction was the most common symptom in the open (42\%) group. In recent years, most cases can be palliated with colonic stents. However, stenting of proximal colonic lesions is difficult because colonoscopic procedures that reach the proximal obstructing site are more technically demanding. ${ }^{26}$ In our study, four converted cases were all colon cancers, and the reasons for conversion were tumor fixation to adjacent organs $(n=3)$ and perforated tumor $(n=1)$. This finding indicates that laparoscopic rectal resection can be a reasonable approach for stage IV disease in the absence of tumor fixation. However, this is a retrospective series, and a future prospective study would be valuable for defining clear indications for laparoscopic rectal surgery in stage IV disease.

Patients with asymptomatic primary tumor were more frequently managed by laparoscopy (colon cancer: $35 \%$ vs $13 \%$ and rectal cancer: $37 \%$ vs $6 \%$ ) in this study. However, Law et al ${ }^{14}$ reported that rates of laparoscopy (5\%) and open surgery $(8 \%)$ were not different for resecting asymptomatic primary tumor in patients with stage IV colorectal cancer. Kim et $\mathrm{al}^{13}$ also reported that rates of laparoscopy (54\%) and open surgery (58\%) were not different for patients who had an asymptomatic primary tumor. In terms of patient factors, mean age varied from 60 to 70 years. ${ }^{11,12,14-18}$ Proportions of male patients were $40 \%-69 \% .{ }^{11-18}$ The proportion of patients with a high ASA score (3 or higher) ranged from $0 \%$ to $17 \%$ of study populations ${ }^{11-15,18}$ and was $18 \%$ in this study. Mean body mass index ranged from 21 to $23 \mathrm{~kg} / \mathrm{m}^{2} .11,15,18$ Peritoneal carcinomatosis was reported in $6 \%-25 \%$ of cases $^{11-14,16,17}$ and was present in $13 \%$ of cases in this study. Among patients, $20 \%-30 \%$ had a history of prior abdominal surgery in previous studies ${ }^{11,16,18}$ and only $5 \%$ fell in this category among our patients. Laparoscopic liver resection rate varied from $1 \%{ }^{18}$ and $8 \%{ }^{14}$ in previous studies and was $13 \%$ in our study. Collectively, these data suggest that patient factors such as higher ASA score $(\geq 3)$ and a history of prior surgery, and tumor factors such as peritoneal carcinomatosis 
or liver metastasis may not be absolute contraindications for laparoscopy. We believe that laparoscopic liver resection can be more actively considered in patients with liver metastasis. It is known that segments II, III, IVb, V, or VI metastases are more convenient for a laparoscopic approach than segments IVa, VII, or VIII metastases. ${ }^{27}$ Indeed, metastatic nodules in segments II, III, IVb, V, or VI were more frequently resected with laparoscopy (100\%) compared with open surgery $(56 \%)$ in our study. Even in patients with segments IVa, VII, or VIII metastases, laparoscopic radiofrequency ablation offers an alternative to resection.

In addition to patient factors, surgeon factors such as level of technical skill and experience are crucial for laparoscopic surgery. The surgeon-dependent factor was controlled in this study, as all laparoscopic and open surgeries were performed by two experienced colorectal surgeons who have extensive experience with both laparoscopic and open surgery. ${ }^{28}$

\section{Short-term and oncologic outcomes}

As expected, laparoscopy was associated with short-term advantages such as less ICU admission, shorter time to soft diet, ${ }^{13,16,17}$ reduced length of hospital stay, ${ }^{11-18}$ and shorter time from surgery to chemotherapy commencement in both colon and rectal cancer patients. ${ }^{16}$ In the current study, the laparoscopy group started chemotherapy 8 days earlier in colon cancer and 9 days earlier in rectal cancer. Wang et $\mathrm{al}^{16}$ observed that mean time to initiate chemotherapy was 3.6 days shorter in their laparoscopy group, but other studies did not find any difference. ${ }^{11,17,18}$ The postoperative complication rate varied from $9 \%$ to $32.8 \%$ in previous reports ${ }^{11-18}$ and was $26 \%$ in this study.

Median survival was reported at 16-25.9 months ${ }^{11,14,16,18}$ and earlier studies demonstrated comparable oncologic outcomes of laparoscopy in stage IV disease. ${ }^{11-16,18}$ We also observed that cancer-specific and progression-free survival rates of colon and rectal cancers were similar between the laparoscopy and open surgery groups. Interestingly, patients who underwent laparoscopic surgery started chemotherapy 8 (colon cancer) and 9 days (rectal cancer) sooner; however, earlier use of chemotherapy did not influence cancer-specific or progression-free survival.

According to the current National Comprehensive Cancer Network guidelines, resection of a primary tumor is recommended only if patients present with primary tumor-related symptoms such as obstruction, hemorrhage, and perforation. ${ }^{8,9}$ However, asymptomatic patients can still undergo surgery for primary tumor-induced problems during their chemotherapy courses. In addition, a number of investigators demonstrated that primary tumor resection improved oncologic outcomes. ${ }^{29-31}$ Thus, there remains controversy regarding which is a better first approach in stage IV patients with asymptomatic primary tumor. In this study, decisions regarding surgery or chemotherapy were made after multidisciplinary team meetings. ${ }^{32}$ This study is limited because a small number of patients were included and the data were collected retrospectively. Various clinical scenarios such as survival according to the use of chemotherapy or chemotherapy regimens could not be stratified due to the limited study population. In terms of oncologic outcomes, this study has many biases, and definite conclusions could not be drawn. However, this is the first study to investigate factors related to the choice of laparoscopy in patients with stage IV disease.

\section{Conclusion}

In summary, laparoscopy can be selected as an initial approach in patients with a primary tumor without adjacent organ invasion, and patients without primary tumor-related symptoms, based on our findings. In selected stage IV patients, tumor factors such as primary rectal tumor, peritoneal carcinomatosis, or liver metastasis may not be absolute contraindications for laparoscopic approach. Laparoscopy for primary tumor resection yielded favorable short-term and similar oncologic outcomes. Further studies in larger cohorts are needed to develop optimal indications for laparoscopy in patients with stage IV colorectal cancer.

\section{Acknowledgment}

The authors would like to thank Hyun Jun Kwon for helping them to maintain a colorectal database and perform statistical analyses.

\section{Author contributions}

Study concept and design: YWK, IYK, and BRK. Acquisition and interpretation of data: YWK, BRK, and HSK. Drafting of the manuscript: YWK, BRK, and HSK. Critical revision of the manuscript: YWK, IYK, and BRK.

\section{Disclosure}

The authors report no conflicts of interest in this work.

\section{References}

1. Veldkamp R, Kuhry E, Hop WC, et al. Laparoscopic surgery versus open surgery for colon cancer: short-term outcomes of a randomised trial. Lancet Oncol. 2005;6(7):477-484.

2. Guillou PJ, Quirke P, Thorpe H, et al. Short-term endpoints of conventional versus laparoscopic-assisted surgery in patients with colorectal cancer (MRC CLASICC trial): multicentre, randomised controlled trial. Lancet. 2005;365(9472):1718-1726. 
3. Clinical Outcomes of Surgical Therapy Study Group. A comparison of laparoscopically assisted and open colectomy for colon cancer. $N$ Engl J Med. 2004;350(20):2050-2059.

4. Bonjer HJ, Deijen CL, Abis GA, et al. A randomized trial of laparoscopic versus open surgery for rectal cancer. $N$ Engl J Med. 2015;372(14): 1324-1332.

5. Jayne DG, Thorpe HC, Copeland J, Quirke P, Brown JM, Guillou PJ. Five-year follow-up of the Medical Research Council CLASICC trial of laparoscopically assisted versus open surgery for colorectal cancer. Br J Surg. 2010;97(11):1638-1645.

6. Tebbutt NC, Norman AR, Cunningham D, et al. Intestinal complications after chemotherapy for patients with unresected primary colorectal cancer and synchronous metastases. Gut. 2003;52(4):568-573.

7. Mella J, Biffin A, Radcliffe AG, Stamatakis JD, Steele RJ. Populationbased audit of colorectal cancer management in two UK health regions. Colorectal Cancer Working Group, Royal College of Surgeons of England Clinical Epidemiology and Audit Unit. Br J Surg. 1997;84(12): 1731-1736

8. National Comprehensive Cancer Network. National Comprehensive Cancer Network guidelines, colon cancer (Version 2.2015). Available from: http://www.nccn.org/professionals/physician_gls/pdf/colon.pdf. Accessed May 1, 2015.

9. National Comprehensive Cancer Network. National Comprehensive Cancer Network guidelines, rectal cancer (Version 2.2015). Available from: http://www.nccn.org/professionals/physician_gls/pdf/rectal.pdf. Accessed May 1, 2015.

10. Kim YW, Kim IY. The role of surgery for asymptomatic primary tumors in unresectable stage IV colorectal cancer. Ann Coloproctol. 2013;29(2):44-54.

11. Akagi T, Inomata M, Kitano S, et al. Multicenter study of short- and long-term outcomes of laparoscopic palliative resection for incurable, symptomatic stage IV colorectal cancer in Japan. J Gastrointest Surg. 2013;17(4):776-783.

12. Allaix ME, Degiuli M, Giraudo G, Marano A, Morino M. Laparoscopic versus open colorectal resections in patients with symptomatic stage IV colorectal cancer. Surg Endosc. 2012;26(9):2609-2616.

13. Kim JW, Park JW, Park SC, Kim SY, Baek JY, Oh JH. Clinical outcomes of laparoscopic versus open surgery for primary tumor resection in patients with stage IV colorectal cancer with unresectable metastasis. Surg Today. 2015;45(6):752-758.

14. Law WL, Fan JK, Poon JT, Choi H, Lo OS. Laparoscopic bowel resection in the setting of metastatic colorectal cancer. Ann Surg Oncol. 2008;15(5):1424-1428.

15. Ohta K, Takemasa I, Uemura M, et al. Laparoscopic surgery for stage IV colorectal cancer. Surg Laparosc Endosc Percutan Tech. 2014;24(2): $153-157$.

16. Wang JH, King TM, Chang MC, Hsu CW. Comparison of the feasibility of laparoscopic resection of the primary tumor in patients with stage IV colon cancer with early and advanced disease: the short- and long-term outcomes at a single institution. Surg Today. 2013;43(10):1116-1122.

17. Akagi T, Inomata M, Etoh T, Yasuda K, Shiraishi N, Kitano S. Laparoscopic versus conventional palliative resection for incurable, symptomatic stage IV colorectal cancer: impact on short-term results. Surg Laparosc Endosc Percutan Tech. 2011;21(3):184-187.

OncoTargets and Therapy

\section{Publish your work in this journal}

OncoTargets and Therapy is an international, peer-reviewed, open access journal focusing on the pathological basis of all cancers, potential targets for therapy and treatment protocols employed to improve the management of cancer patients. The journal also focuses on the impact of management programs and new therapeutic agents and protocols on
18. Hida K, Hasegawa S, Kinjo Y, et al. Open versus laparoscopic resection of primary tumor for incurable stage IV colorectal cancer: a large multicenter consecutive patients cohort study. Ann Surg. 2012;255(5): 929-934.

19. von Elm E, Altman DG, Egger M, Pocock SJ, Gotzsche PC, Vandenbroucke JP. The Strengthening the Reporting of Observational Studies in Epidemiology (STROBE) statement: guidelines for reporting observational studies. Lancet. 2007;370(9596):1453-1457.

20. Kim IY, Kim BR, Kim YW. The short-term and oncologic outcomes of laparoscopic versus open surgery for T4 colon cancer. Surg Endosc. Epub 2015 Jun 27.

21. Kim IY, Kim BR, Kim YW. Outcomes of laparoscopic and open surgery for colorectal cancer in the emergency setting. In Vivo. 2015;29(2): 295-300.

22. Kim YW, Choi EH, Kim IY, Kwon HJ, Ahn SK. The impact of mechanical bowel preparation in elective colorectal surgery: a propensity score matching analysis. Yonsei Med J. 2014;55(5):1273-1280.

23. Dindo D, Demartines N, Clavien PA. Classification of surgical complications: a new proposal with evaluation in a cohort of 6336 patients and results of a survey. Ann Surg. 2004;240(2):205-213.

24. Kumar AS, Lee SW. Laparoscopy in colorectal surgery. Surg Clin North Am. 2013;93(1):217-230.

25. Marks JH, Kawun UB, Hamdan W, Marks G. Redefining contraindications to laparoscopic colorectal resection for high-risk patients. Surg Endosc. 2008;22(8):1899-1904.

26. Jung MK, Park SY, Jeon SW, et al. Factors associated with the longterm outcome of a self-expandable colon stent used for palliation of malignant colorectal obstruction. Surg Endosc. 2010;24(3):525-530.

27. Winslow E, Hawkins WG. Laparoscopic resection of the liver for cancer. Surg Oncol Clin N Am. 2013;22(1):75-89, vi.

28. Kim DH, Kim IY, Kim BR, Kim YW. Factors affecting the selection of minimally invasive surgery for stage $0 /$ I colorectal cancer. Int J Surg. 2015;16(Pt A):44-48.

29. Ferrand F, Malka D, Bourredjem A, et al. Impact of primary tumour resection on survival of patients with colorectal cancer and synchronous metastases treated by chemotherapy: results from the multicenter, randomised trial Federation Francophone de Cancerologie Digestive 9601. Eur J Cancer. 2013;49(1):90-97.

30. Karoui M, Roudot-Thoraval F, Mesli F, et al. Primary colectomy in patients with stage IV colon cancer and unresectable distant metastases improves overall survival: results of a multicentric study. Dis Colon Rectum. 2011;54(8):930-938.

31. Venderbosch S, de Wilt JH, Teerenstra S, et al. Prognostic value of resection of primary tumor in patients with stage IV colorectal cancer: retrospective analysis of two randomized studies and a review of the literature. Ann Surg Oncol. 2011;18(12):3252-3260.

32. Kim IY, Kim BR, Kim YW. Factors affecting use and delay ( $\geq 8$ weeks) of adjuvant chemotherapy after colorectal cancer surgery and the impact of chemotherapy-use and delay on oncologic outcomes. PLoS One. 2015;10(9):e0138720

patient perspectives such as quality of life, adherence and satisfaction The manuscript management system is completely online and includes a very quick and fair peer-review system, which is all easy to use. Visit http://www.dovepress.com/testimonials.php to read real quotes from published authors. 